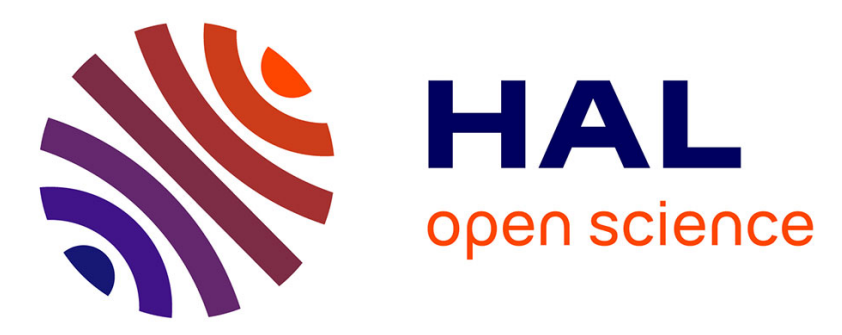

\title{
Counterion-Controlled Formation of an Octanuclear Uranyl Cage with cis-1,2-Cyclohexanedicarboxylate Ligands
}

Pierre Thuéry, Youssef Atoini, Jack Harrowfield

\section{- To cite this version:}

Pierre Thuéry, Youssef Atoini, Jack Harrowfield. Counterion-Controlled Formation of an Octanuclear Uranyl Cage with cis-1,2-Cyclohexanedicarboxylate Ligands. Inorganic Chemistry, In press, 57, pp.6283-6288. 10.1021/acs.inorgchem.8b00147 . cea-01792915

\section{HAL Id: cea-01792915 https://hal-cea.archives-ouvertes.fr/cea-01792915}

Submitted on 16 May 2018

HAL is a multi-disciplinary open access archive for the deposit and dissemination of scientific research documents, whether they are published or not. The documents may come from teaching and research institutions in France or abroad, or from public or private research centers.
L'archive ouverte pluridisciplinaire HAL, est destinée au dépôt et à la diffusion de documents scientifiques de niveau recherche, publiés ou non, émanant des établissements d'enseignement et de recherche français ou étrangers, des laboratoires publics ou privés. 


\title{
Counterion-Controlled Formation of an Octanuclear Uranyl Cage with cis-1,2-Cyclohexanedicarboxylate Ligands
}

\author{
Pierre Thuéry, ${ }^{* \dagger}$ Y Youssef Atoini ${ }^{\ddagger}$ and Jack Harrowfield ${ }^{\ddagger}$ \\ †NIMBE, CEA, CNRS, Université Paris-Saclay, CEA Saclay, 91191 Gif-sur-Yvette, France \\ FISIS, Université de Strasbourg, 8 allée Gaspard Monge, 67083 Strasbourg, France
}

Supporting Information Placeholder

\begin{abstract}
Cyclohexanedicarboxylic acid $\left(c-\mathrm{chdcH}_{2}\right)$ was reacted with uranyl nitrate under (solvo-)hydrothermal conditions in the presence of different possible counterions. Two neutral complexes of 1:1 stoichiometry were obtained, $\left[\mathrm{UO}_{2}\left(c\right.\right.$-chdc)(DMF)] (1) and $\left[\mathrm{UO}_{2}(c\right.$-chdc $\left.)\left(\mathrm{H}_{2} \mathrm{O}\right)\right](\mathbf{2})$, which crystallize as two-dimensional coordination polymers and do not include the additional cations present in solution. In contrast, the complex $\left[\mathrm{NH}_{4}\right]\left[\mathrm{PPh}_{4}\right]\left[\left(\mathrm{UO}_{2}\right)_{8}(c \text {-chdc })_{9}\left(\mathrm{H}_{2} \mathrm{O}\right)_{6}\right] \cdot 3 \mathrm{H}_{2} \mathrm{O}(\mathbf{3})$ crystallized in the presence of $\mathrm{PPh}_{4} \mathrm{Br}$, ammonium cations being generated in situ from acetonitrile hydrolysis. This complex of 8:9 uranium:ligand stoichiometry contains an octanuclear anionic cage of $D_{3}$ symmetry with a pseudo-cubic arrangement of uranium atoms. The ammonium cation is held within the cage through four hydrogen bonds with uranyl oxo groups directed inwards. This cage complex is luminescent, although with a low quantum yield of 0.06 , indicating some potential as a photooxidant of included species.
\end{abstract}

\section{INTRODUCTION}

In the field of oligomeric and polymeric solid state complexes of uranyl ion, ${ }^{1-4}$ polycarboxylic (particularly diand tricarboxylic) acid derivatives of cyclohexane have proven to enable the synthesis of a variety of species. ${ }^{5-15}$ The nature of the latter depends not only on the ring substitution pattern and its stereochemistry but also upon the solvent used for the syntheses and the presence of additional cations. In the case of 1,2-cyclohexanedicarboxylates, the favoured diequatorial disposition of the carboxylate substituents in the trans isomer $\left(t \text {-chdc }{ }^{2-}\right)^{16}$ might be expected to have different consequences to the favoured axial-equatorial disposition for the $c i s\left(c-\mathrm{chdc}^{2-}\right)$. The trans isomer is usually referred to as the racemic form, since it can be separated into configurationally stable $R, R$ and $S, S$ enantiomers, ${ }^{17}$ while the cis is commonly termed the meso form due to the rapid conformational interconversion, in solution, of its $R_{a x}, S_{e q}$ and $R_{e q}, S_{a x}$ enantiomers. In the solid state, however, this conformational equilibrium is blocked and although it is common to find both enantiomers within a crystal lattice, chiral resolution of the $c i$ isomer has been achieved. ${ }^{18}$ Thus, in terms of the stereochemistry of their crystalline complexes, the two diastereoisomeric forms of the acid offer similar possibilities going beyond differences in chelating and bridging modes of coordination. Here, it may be noted that consultation of the Cambridge Structural Database $(C S D \text {, Version 5.38) })^{19}$ shows both $c$ - and $t$-chdc ${ }^{2-}$ appear generally to favour coordination via bridging, although cases of chelation involving both carboxylate groups (not just the common $\kappa^{2} O, O^{\prime}$-chelation by one alone) are known for both.
In the uranyl ion complexes formed with both racemic and $(1 R, 2 R)-t$-chdc ${ }^{2-},{ }^{13,14}$ the bridging role played by the ligands means that ligand-ligand contacts are rather remote. This may explain the formation, besides one- and twodimensional (1D and 2D) polymeric species, of tetranuclear $\left[\left(\mathrm{UO}_{2}\right)_{4}(t \text {-chdc })_{6}\right]^{4-}$ anions which are very similar regardless of whether the acid employed is racemic or enantiomerically pure. Depending on the counterion $\left(\mathrm{NH}_{4}{ }^{+}\right.$, alkali, alkalineearth cations, $\mathrm{Ag}^{\mathrm{I}}$, or $\left.\mathrm{Pb}^{\mathrm{II}}\right)$, these tetrahedral anions are involved in different associations, some of them threedimensional (3D), the most remarkable being the heterometallic cuboidal clusters formed with $\mathrm{Rb}^{\mathrm{I}}$ and $\mathrm{Cs}^{\mathrm{I}}{ }^{\mathrm{I}}{ }^{14}$ Although several cages formed from uranyl ion and organic ligands $4,5,10,13,14,20-23$ (as well as the extensive family of peroxo-linked uranyl nanospheres ${ }^{24-28}$ ) are known, the synthesis of cages sufficiently large to include guest molecules or ions, and particularly cages which may retain photo-oxidant activity, remains a challenge. ${ }^{4}$ So as to establish the influence of the geometry of $\operatorname{chdc}^{2-}$ on cage formation, we have now investigated the uranyl ion complexes formed with $c$ - chdc $^{2-}$ under (solvo)hydrothermal conditions and in the presence of different additional species. Reported here are three complexes thus synthesized and crystallographically characterized, one of them being an octanuclear cage of unprecedented geometry where an influence of the ligand chirality is apparent.

\section{EXPERIMENTAL SECTION}

Synthesis. Caution! ${ }^{238} U$ is a radioactive element, and its complexes must be handled with suitable care and protection. 
$\mathrm{UO}_{2}\left(\mathrm{NO}_{3}\right)_{2} \cdot 6 \mathrm{H}_{2} \mathrm{O}$ (depleted uranium, R. P. Normapur, 99\%) was purchased from Prolabo and cis-1,2cyclohexanedicarboxylic acid $\left(c-\mathrm{chdcH}_{2}\right)$ was from Alfa Aesar. Elemental analyses were performed by MEDAC Ltd. at Chobham, UK.

[UO $\left.\mathrm{O}_{2}(\mathrm{c}-\mathrm{chdc})(\mathrm{DMF})\right]$ (1). $c$-chdcH $\mathrm{H}_{2}(17 \mathrm{mg}, 0.10 \mathrm{mmol})$, $\mathrm{UO}_{2}\left(\mathrm{NO}_{3}\right)_{2} \cdot 6 \mathrm{H}_{2} \mathrm{O}(50 \mathrm{mg}, 0.10 \mathrm{mmol}), \mathrm{Ni}\left(\mathrm{NO}_{3}\right)_{2} \cdot 6 \mathrm{H}_{2} \mathrm{O}(30$ $\mathrm{mg}, 0.10 \mathrm{mmol}), N, N$-dimethylformamide $(0.2 \mathrm{~mL})$, and demineralized water $(0.6 \mathrm{~mL})$ were placed in a $10 \mathrm{~mL}$ tightly closed glass vessel and heated at $140{ }^{\circ} \mathrm{C}$ under autogenous pressure, yielding light yellow crystals of complex $\mathbf{1}$ overnight (7 mg, 14\% yield). Anal. calcd for $\mathrm{C}_{11} \mathrm{H}_{17} \mathrm{NO}_{7} \mathrm{U}$ : C, 25.74; H, 3.34; N, 2.73. Found: C, 25.81; H, 3.23; N, $2.56 \%$.

[UO $\left.\mathrm{O}_{2}(\mathrm{c}-\mathrm{chdc})\left(\mathrm{H}_{2} \mathrm{O}\right)\right]$ (2). $c$-chdcH $\mathrm{H}_{2}(17 \mathrm{mg}, 0.10 \mathrm{mmol})$, $\mathrm{UO}_{2}\left(\mathrm{NO}_{3}\right)_{2} \cdot 6 \mathrm{H}_{2} \mathrm{O}(50 \mathrm{mg}, 0.10 \mathrm{mmol})$, guanidinium nitrate $(24 \mathrm{mg}, 0.20 \mathrm{mmol})$, and demineralized water $(0.7 \mathrm{~mL})$ were placed in a $10 \mathrm{~mL}$ tightly closed glass vessel and heated at $140{ }^{\circ} \mathrm{C}$ under autogenous pressure, yielding light yellow crystals of complex 2 within one month $(8 \mathrm{mg}, 17 \%$ yield). Anal. calcd for $\mathrm{C}_{8} \mathrm{H}_{12} \mathrm{O}_{7} \mathrm{U}$ : C, 20.97; H, 2.64. Found: C, $20.91 ; \mathrm{H}, 2.66 \%$. The same complex was also obtained in experiments in which guanidinium nitrate was replaced by $\mathrm{NaNO}_{3}$ or $\mathrm{KNO}_{3}$.

$\left[\mathrm{NH}_{4}\right]\left[\mathrm{PPh}_{4}\right]\left[\left(\mathrm{UO}_{2}\right)_{8}(\mathrm{c}-\mathrm{chdc})_{9}\left(\mathrm{H}_{2} \mathrm{O}\right)_{6}\right] \cdot 3 \mathrm{H}_{2} \mathrm{O} \quad$ (3). $\quad c-\mathrm{chdcH}_{2}$ (17 mg, $0.10 \mathrm{mmol}), \mathrm{UO}_{2}\left(\mathrm{NO}_{3}\right)_{2} \cdot 6 \mathrm{H}_{2} \mathrm{O}$ (35 mg, $\left.0.07 \mathrm{mmol}\right)$, tetraphenylphosphonium bromide (42 $\mathrm{mg}, 0.10 \mathrm{mmol})$, acetonitrile $(0.2 \mathrm{~mL})$, and demineralized water $(0.8 \mathrm{~mL})$ were placed in a $10 \mathrm{~mL}$ tightly closed glass vessel and heated at $140{ }^{\circ} \mathrm{C}$ under autogenous pressure, yielding light yellow crystals of complex $\mathbf{3}$ within two weeks (29 mg, 79\% yield based on U). Anal. calcd for $\mathrm{C}_{96} \mathrm{H}_{132} \mathrm{NO}_{61} \mathrm{PU}_{8}$ : C, 27.38; $\mathrm{H}$, 3.16. Found: C, 27.74; H, 2.92.

Crystallography. Crystallographic data were collected at $150(2) \mathrm{K}$ on a Nonius Kappa-CCD area-detector diffractometer using graphite-monochromated Mo $\mathrm{K} \alpha$ radiation $(\lambda=0.71073 \AA) .{ }^{29}$ The crystals were introduced into glass capillaries with a protecting Paratone-N oil (Hampton Research) coating. The unit cell parameters were determined from ten frames, then refined on all data. The data (combinations of $\varphi$ - and $\omega$-scans with a minimum redundancy of 4 for $90 \%$ of the reflections) were processed with HKL2000. ${ }^{30}$ Absorption effects were corrected empirically with the program SCALEPACK. ${ }^{30}$ The structures were solved by intrinsic phasing with SHELXT, ${ }^{31}$ and refined by full-matrix least-squares on $F^{2}$ with SHELXL-2014. ${ }^{32}$ All non-hydrogen atoms were refined with anisotropic displacement parameters. The hydrogen atoms bound to oxygen and nitrogen atoms were retrieved from difference Fourier maps, and the carbon-bound hydrogen atoms were introduced at calculated positions; all hydrogen atoms were treated as riding atoms with an isotropic displacement parameter equal to 1.2 times that of the parent atom ( 1.5 for $\mathrm{CH}_{3}$, with optimized geometry). The drawings were made with ORTEP- $3^{33}$ and VESTA, ${ }^{34}$ and the topological analyses were conducted with TOPOS. ${ }^{35}$ Special details are as follows.

Compound 1. The cyclohexyl ring and one of the carboxylate carbon atoms are disordered over two positions which were refined with occupancy parameters constrained to sum to unity; the disorder of the second carboxylate carbon atom and the oxygen atoms was not resolved. Restraints were applied for several bond lengths and for displacement parameters in the disordered parts.

Compound 3. Two carboxylate oxygen atoms (O15 and O16) are disordered over two positions which were refined with occupancy parameters constrained to sum to unity; further possible disorder on other carboxylate oxygen atoms could not be resolved. One aromatic ring of the counter-ion is disordered over three positions related by a threefold rotation axis, one position having been refined as an idealized hexagon. The structure has been refined as corresponding to a two-component inversion twin, with a Flack parameter of $0.561(11)$.

Crystal data for 1. $\mathrm{C}_{11} \mathrm{H}_{17} \mathrm{NO}_{7} \mathrm{U}, M=513.28$, monoclinic, space group $P 22_{1} / c, a=10.0016(5), b=10.5544(7), c=$ $14.0906(8) \AA, \beta=100.435(4)^{\circ}, V=1462.82(15) \AA^{3}, Z=4$. Refinement of 246 parameters on 2752 independent reflections out of 37879 measured reflections $\left(R_{\text {int }}=0.031\right)$ led to R1 $=0.039, w \mathrm{R} 2=0.097, S=1.049, \Delta \rho_{\min }=-$ $0.96, \Delta \rho_{\max }=0.86 \mathrm{e}^{-3}$.

Crystal data for 2. $\mathrm{C}_{8} \mathrm{H}_{12} \mathrm{O}_{7} \mathrm{U}, M=458.21$, monoclinic, space group $P 2_{1} / n, a=8.7749(7), b=9.4946(5), c=$ 25.5746(18) $\AA, \quad \beta=95.768(5)^{\circ}, V=2119.9(3) \AA^{3}, Z=8$. Refinement of 289 parameters on 4030 independent reflections out of 61177 measured reflections $\left(R_{\text {int }}=0.045\right)$ led to R1 $=0.048, w \mathrm{R} 2=0.092, S=1.179, \Delta \rho_{\min }=-$ $1.50, \Delta \rho_{\max }=1.92 \mathrm{e}^{-3}$.

Crystal data for 3. $\mathrm{C}_{96} \mathrm{H}_{132} \mathrm{NO}_{61} \mathrm{PU}_{8}, \quad M=4211.23$, trigonal, space group P31c, $a=19.1042(3), c=18.8836$ (4) $\AA, V=5968.6(2) \AA^{3}, Z=2$. Refinement of 546 parameters on 7483 independent reflections out of 159700 measured reflections $\left(R_{\text {int }}=0.027\right)$ led to $\mathrm{R} 1=0.030$, wR2 $=0.068, S$ $=1.036, \Delta \rho_{\min }=-2.01, \Delta \rho_{\max }=1.74 \mathrm{e}^{-3}$.

Luminescence measurements. Steady-state emission spectra were recorded on a Horiba Jobin-Yvon IBH FL-322 Fluorolog 3 spectrometer equipped with a $450 \mathrm{~W}$ xenon arc lamp, double-grating excitation, and emission monochromators $\left(2.1 \mathrm{~nm} \mathrm{~mm}^{-1}\right.$ of dispersion; 1200 grooves $\mathrm{mm}^{-1}$ ) and a TBX-04 single photon-counting detector. Emission and excitation spectra were corrected for source intensity (lamp and grating) and emission spectral response (detector and grating) by standard correction curves. The quantum yield measurements were performed by using an absolute photoluminescence quantum yield spectrometer Quantaurus C11347 (Hamamatsu, Japan) exciting the sample between $\lambda_{\text {exc }}=300$ and $400 \mathrm{~nm}$.

\section{RESULTS AND DISCUSSION}

Crystal Structures. The two complexes $\left[\mathrm{UO}_{2}(c-\right.$ chdc)(DMF)] (1) and $\left[\mathrm{UO}_{2}\left(c\right.\right.$-chdc) $\left.\left(\mathrm{H}_{2} \mathrm{O}\right)\right](2)$ were obtained in 3:1 water/DMF in the presence of nickel(II) nitrate, or in pure water in the presence of guanidinium nitrate, respectively, but neither of the additional species is present as a counterion. In complex $\mathbf{1}$, the pentagonal bipyramidal uranium atom is chelated by one carboxylate [ $\mathrm{U}-\mathrm{O}$ bond lengths $2.427(6)$ and $2.442(7) \AA]$ and bound to two 
monodentate carboxylate donors [2.292(6) and 2.329(8) A] and one DMF molecule [2.405(7) A] (Figures 1 and S1, Supporting Information). Both metal and $c$-chdc ${ }^{2-}$ are 3 -fold nodes in the 2D network parallel to $\left(\begin{array}{lll}1 & 0 & 0\end{array}\right)$, which has the point (Schläfli) symbol $\left\{4.8^{2}\right\}$ and the common fes topological type. Complex $\mathbf{1}$ crystallizes in a centrosymmetric space group and both enantiomers are present in each layer.

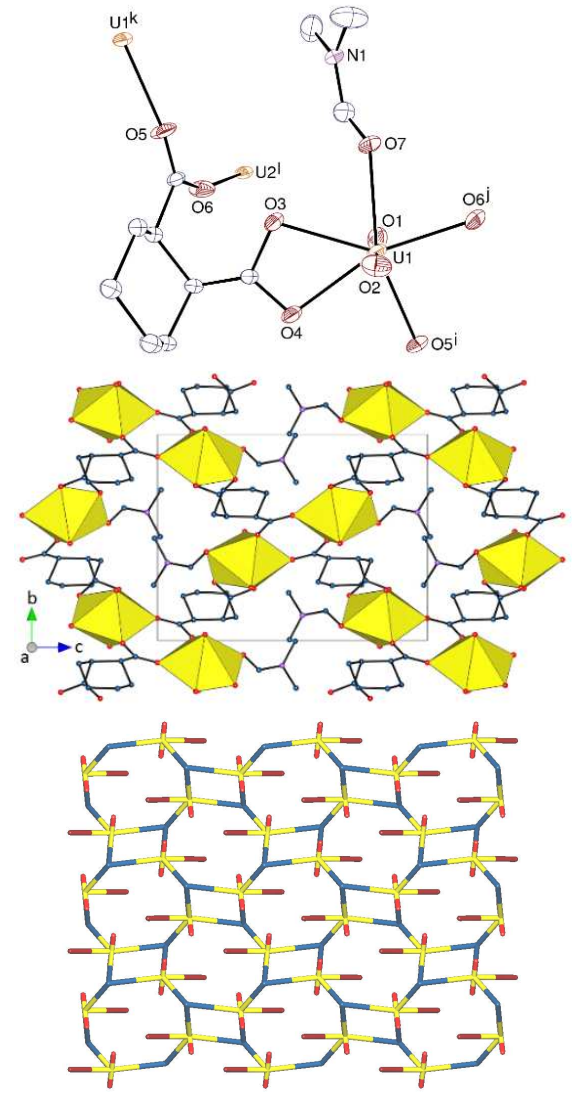

Figure 1. Top: View of complex 1 . Symmetry codes: $\mathrm{i}=x, 1 / 2-y, z+1 / 2$; $\mathrm{j}=-x, y-1 / 2 ; 3 / 2-z ; \mathrm{k}=x, 1 / 2-y, z-1 / 2 ; 1=-x, y+1 / 2 ; 3 / 2-z$. Middle: View of the $2 \mathrm{D}$ assembly with uranium coordination polyhedra in yellow. Hydrogen atoms are omitted in both views. Bottom: Nodal representation of the fes network viewed down the $a$ axis and with the $b$ axis vertical (yellow: uranium, red: oxygen, blue: dicarboxylate ligand, dark red: DMF).

One of the two independent uranium atoms in 2 (U1) is chelated by one carboxylate group [2.434(8) and 2.484(8) $\AA$ ], both $\mathrm{U} 1$ and $\mathrm{U} 2$ being also bound to three monodentate carboxylate donors [2.310(9)-2.393(8) $\AA$ ], with two water ligands on U2 ensuring five coordination in the equatorial plane (Figures 2 and S2). One of the two $c$-chdc ${ }^{2-}$ ligands is chelating $\left(\kappa^{2} O, O^{\prime}\right)$ and bridging bidentate $\left(\mu_{2}-\kappa^{1} O: \kappa^{1} O^{\prime}\right)$, as that in $\mathbf{1}$, while the second is chelating through its two carboxylate groups, each of them being bridging bidentate. The uranium atoms are thus 4-fold nodes or simple links, and the ligands 3 -fold nodes in the $2 \mathrm{D}$ network parallel to ( 0 0 1), which can best be viewed as a square lattice with decorating $\mathrm{UO}_{2}\left(\mathrm{H}_{2} \mathrm{O}\right)_{2}$ groups. Here, each layer is homochiral, and the chirality alternates from one to the next.
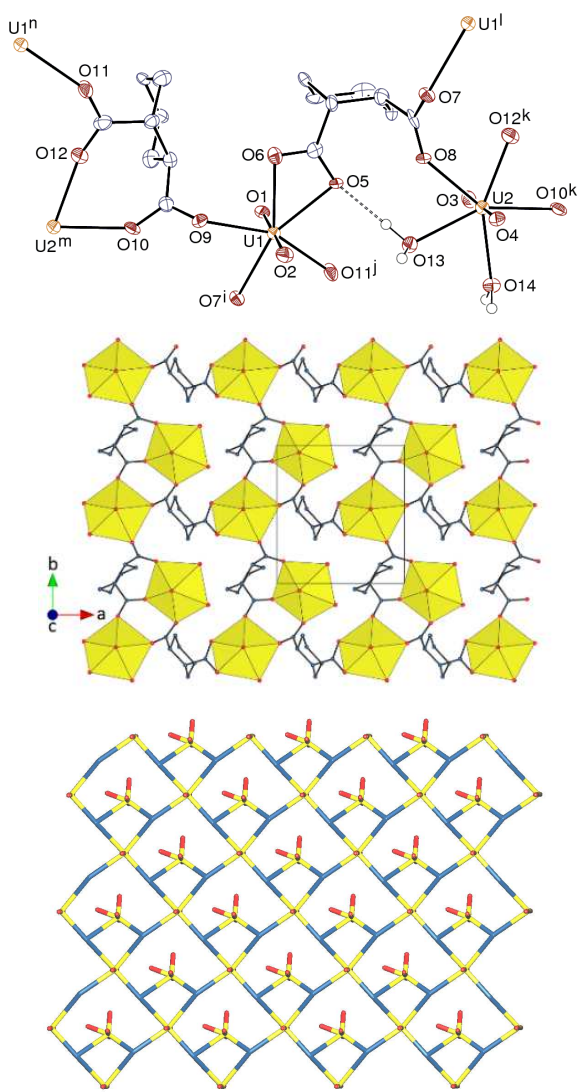

Figure 2. Top: View of complex 2, with carbon-bound hydrogen atoms omitted and hydrogen bond shown as a dashed line. Symmetry codes: $\mathrm{i}=x$ $+1, y, z ; \mathrm{j}=x, y+1, z ; \mathrm{k}=x-1, y+1, z ; \mathrm{l}=x-1, y, z ; \mathrm{m}=x+1, y-1, z ;$ $\mathrm{n}=x, y-1, z$. Middle: View of the 2D network. Bottom: Nodal

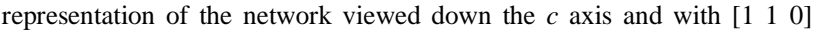
horizontal (yellow: uranium, red: oxygen, blue: dicarboxylate ligand).

In contrast to $\mathbf{1}$ and $\mathbf{2}$, the complex $\left[\mathrm{NH}_{4}\right]\left[\mathrm{PPh}_{4}\right]\left[\left(\mathrm{UO}_{2}\right)_{8}(c \text {-chdc })_{9}\left(\mathrm{H}_{2} \mathrm{O}\right)_{6}\right] \cdot 3 \mathrm{H}_{2} \mathrm{O}$ involves a discrete anionic, octanuclear species forming a cage about the ammonium ion. Complex $\mathbf{3}$ crystallizes in the trigonal, non-centrosymmetric space group $P 31 c$ with four independent uranyl ions (two of which, U1 and $\mathrm{U} 2$, are located on a threefold rotation axis), and three $c$-chdc ${ }^{2-}$ ligands (Figure 3). U1 and U2 are chelated by three carboxylate groups [U-O bond lengths in the range of 2.470(8)-2.501(8) $\mathrm{A}]$ and they are thus in a hexagonal bipyramidal environment. U3 and U4 are chelated by only one carboxylate group [2.404(9)$2.458(8) \AA]$ and bound to two monodentate carboxylate donors partially affected by disorder [2.26(2)-2.44(2) $\AA]$ and one water molecule, being thus in pentagonal bipyramidal environments. Two ligands are $\kappa^{2} O, O^{\prime}-$ chelating $/ \mu_{2}-\kappa^{1} O: \kappa^{1} O^{\prime}$-bridging bidentate, while the third is bis- $\kappa^{2} O, O^{\prime}$-chelating (a coordination mode adopted by all the ligands in the tetrahedral cages based on $t$ - $\mathrm{chdc}^{2-}$ ), and the cage in $\mathbf{3}$ is homochiral. The eight uranium atoms are at the vertices of a nearly perfect cube with side lengths in the range of 5.3669(6)$5.6061(6) \AA$ and $\mathrm{U} \cdot \mathrm{U} \cdot \mathrm{U} \cdot \mathrm{U}$ angles of $85.304(10)-$ 
$96.846(12)^{\circ}$. The side lengths are smaller than those in the tetrahedral cages with $t$-chdc ${ }^{2-}(5.82-6.95 \AA)$. Up to now, two different arrangements of the ligands have been found in homoleptic uranyl octanuclear cages, one in which they span the cube edges, found with $(1 R, 3 S)$ (+)-camphorate, ${ }^{21}$ and another in which they lie above the face centres, found with Kemp's triacid, ${ }^{9,10}$ and also with $p$-carboxylatocalix[4] $\operatorname{arene}^{23}$ (Figure 4). The arrangement of ligands in $\mathbf{3}$ is unique, with a mixture
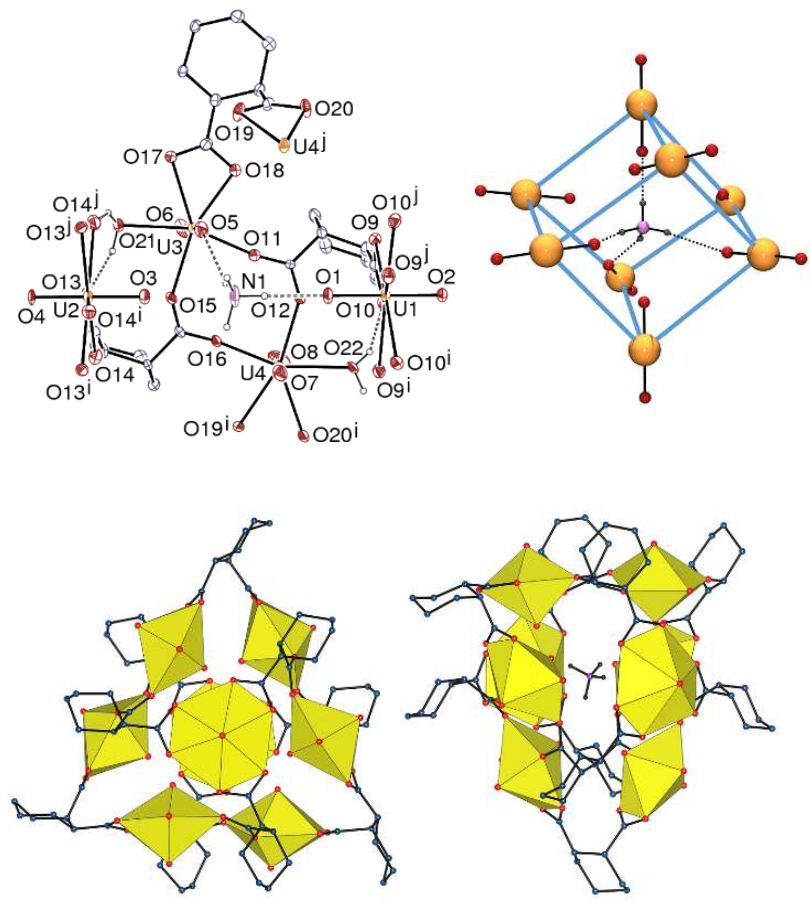

Figure 3. Top: View of complex $\mathbf{3}$ showing the asymmetric unit and the surrounding atoms, with the $\mathrm{PPh}_{4}^{+}$counterion, solvent molecules and carbon-bound hydrogen atoms omitted, and view of the cuboidal arrangement of uranyl ions with the included $\mathrm{NH}_{4}{ }^{+}$cation. Hydrogen bonds are shown as dashed lines. Symmetry codes: $\mathrm{i}=1-y, x-y, z ; \mathrm{j}=y-x+1$, $1-x ; z$. Bottom: two views of the octanuclear cage.

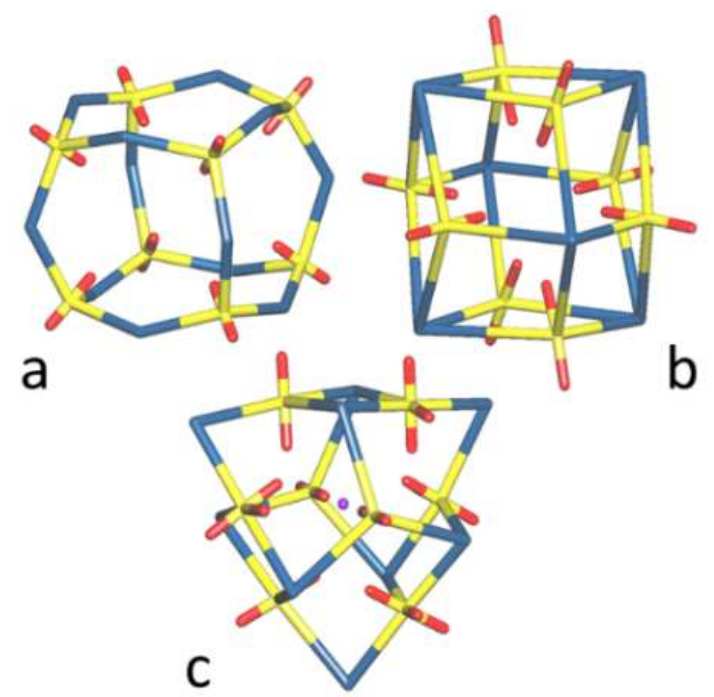

Figure 4. Simplified views of the octanuclear cages in the complexes with $(1 R, 3 S)-(+)$-camphorate (a), Kemp's triacid (b), and $c$-chdc ${ }^{2-}$ in 3 (c). Yellow, uranium, red: oxygen, blue: carboxylate ligand, purple: $\mathrm{NH}_{4}{ }^{+}$. of 2- and 3-fold-coordinated ligands. The two uranium atoms on the rotation axis are connected to three doublybridged dinuclear units, these being further bound to one another by the twofold connecting ligands to form a trigonal equatorial belt. The tetrahedral cage $\mathrm{U}_{4} \mathrm{~L}_{6}$ contains only 6membered rings (containing three 3 -fold $U$ nodes and three $\mathrm{L}$ links), the cuboid $\mathrm{U}_{8} \mathrm{~L}_{12}$ (a) only 8-membered rings (four 3-fold $U$ nodes, four $\mathrm{L}$ links), the cuboid $\mathrm{U}_{8} \mathrm{~L}_{6}$ (b) only 4membered rings (two 3-fold $\mathrm{U}$ nodes and two 4-fold $\mathrm{L}$ nodes), while the present $\mathrm{U}_{8} \mathrm{~L}_{9}$ cage displays 4-membered rings (two $\mathrm{U}$ and two L 3-fold nodes) and 6-membered ones (three U and two L 3-fold nodes, and one L link). Whereas the cages a and b have full cubic $O_{\mathrm{h}}$ point group symmetry, the cage c has only approximate $D_{3}$ symmetry. The nearly perfect cubic $\mathrm{U}_{8}$ arrangement resulting from such an irregular connectivity as found in $\mathbf{3}$ is thus all the more remarkable.

Although a very frequently encountered counterion, $\mathrm{PPh}_{4}{ }^{+}$has never been used before as a structure-inducing species in uranyl coordination polymer synthesis. Here it is accompanied by $\mathrm{NH}_{4}{ }^{+}$, presumed to have been formed in situ from acetonitrile hydrolysis possibly catalyzed by $\mathrm{U}^{\mathrm{VI}}$, as previously observed. ${ }^{14,36,37}$ The latter cation is included in the cage cavity, and it forms four hydrogen bonds with uranyl oxo groups directed inwards [N... O distances 2.89(3) and 3.246(14) $\AA, \mathrm{H} \cdots \mathrm{O} 1.97$ and $2.34 \AA$, N-H..O 180 and $153^{\circ}$ ]. It may be surmised that the ammonium cation plays a structure-directing role here, as it is also possibly the case in the formation of nanotubules with tricarballylic acid. ${ }^{37}$ When viewed down the $c$ axis, the packing displays large channels centered on threefold rotation axes, with a diameter of $\sim 9 \AA$, which are occupied by columns of $\mathrm{PPh}_{4}{ }^{+}$ counterions (Figure 5), an indication that the latter may also play a significant role as templates.

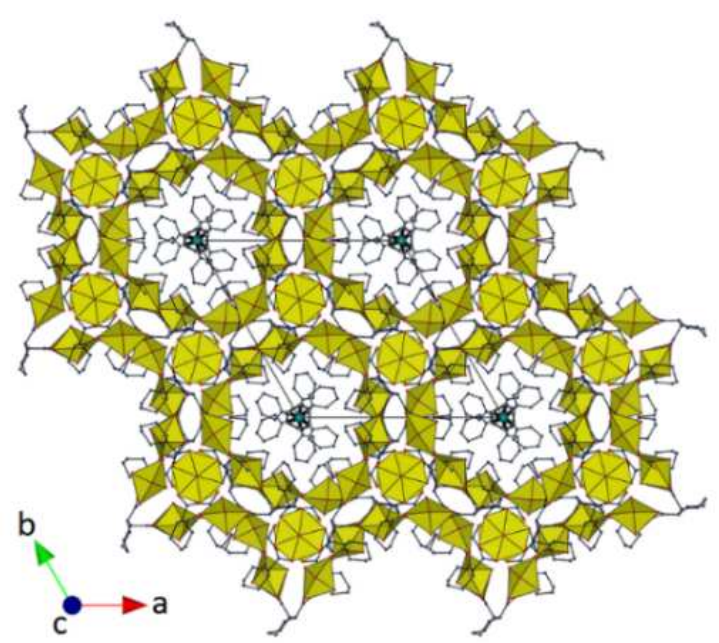

Figure 5. View of the packing in $\mathbf{3}$ with solvent molecules and hydrogen atoms omitted.

Reasons for the difference between the tetranuclear cages obtained with both rac- and $(1 R, 2 R)-t$-chdc ${ }^{2-}$ and the octanuclear complex 3 obtained with $c$ - $\operatorname{chdc}^{2-}$ appear to be multiple. We have found that uranyl complexes with both rac- and $(1 R, 2 R)-t$-chdc ${ }^{2-}$ can only be crystallized with $\mathrm{PPh}_{4}{ }^{+}$ counterions when DMF is used as a cosolvent, but that the $\mathrm{H}_{2} \mathrm{NMe}_{2}{ }^{+}$cations potentially present in the preparative 
media are not found in the solid complexes, which crystallize as $1 \mathrm{D}$ polymers and will be described elsewhere. As well, $\mathrm{NH}_{4}{ }^{+}$does not suffice to induce the formation of an octanuclear cage with rac-t-chdc ${ }^{2-}$, as shown by the tetranuclear species $\left[\mathrm{NH}_{4}\right]_{4}\left[\left(\mathrm{UO}_{2}\right)_{4}(t \text {-chdc })_{6}\right] .{ }^{14}$ Changing the ligand conformation from $e q, e q$ in the trans species to ax,eq in the cis appears as the key parameter although reasons for the homochiral character of the cages in $\mathbf{3}$ remain obscure.

Luminescence Properties. Emission spectra under excitation at a wavelength of $420 \mathrm{~nm}$ were recorded in the solid state for all compounds (Figures 6 and S3). Complex $\mathbf{1}$, and in a lesser measure $\mathbf{2}$, display intense and well-resolved spectra with four main maxima $\left(S_{10}\right.$ $\rightarrow S_{0 v}(\nu=0-4)$ electronic transitions $\left.{ }^{38}\right)$ at $488,509,533$ and $558 \mathrm{~nm}$, and 494, 516, 539 and $565 \mathrm{~nm}$, respectively, both in the range generally observed for pentagonal bipyramidal complexes, ${ }^{15}$ albeit on the highenergy side. Unsurprisingly for a complex with a mixture of penta- and hexagonal bipyramidal uranium environments, the spectrum of $\mathbf{3}$ shows a series of badly resolved peaks, the first intense maximum, at $481 \mathrm{~nm}$, being typical of triply chelated carboxylate uranyl complexes. $^{15}$ A photoluminescence quantum yield (PLQY) of 0.06 was measured for compound 3 . Unfortunately, due to lack of material and instrument limitations, the PLQY of complexes $\mathbf{1}$ and $\mathbf{2}$ could not be determined. While it must be noted that complex $\mathbf{3}$ is the least luminescent compound in the series, all the samples having been measured using the same parameters (excitation wavelength, excitation and emission slits, amount of material and integration time), it does exhibit significant luminescence, so that this result is promising in regard to possible photocatalytic applications.

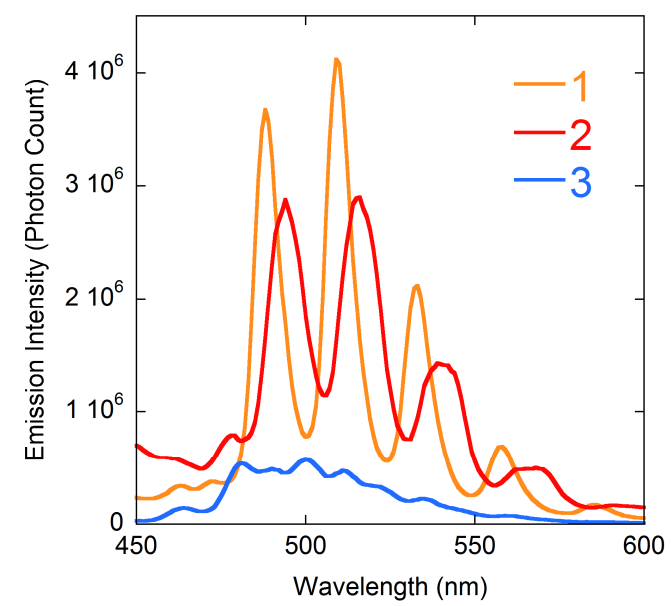

Figure 6. Solid state emission spectra of complexes 1-3 $\left(\lambda_{\text {exc }}=420 \mathrm{~nm}\right)$.

\section{CONCLUSIONS}

We have described three uranyl ion complexes with cis1,2-cyclohexanedicarboxylate ligands synthesized in the presence of different potential counterions and organic cosolvents. While two of these compounds crystallize as neutral 2D assemblies, the third, synthesized in the presence of $\mathrm{PPh}_{4}{ }^{+}$and $\mathrm{NH}_{4}{ }^{+}$cations, provides a new example of a homoleptic uranyl octanuclear species displaying a connectivity different from that in the previously reported octanuclear cages involving different polycarboxylate ligands. This result adds to a family where the cage interior can be considered as hydrophilic due to the inward-pointing array of uranyl oxo groups, this array being suitable for guest inclusion through hydrogen bonding. In relation to such guest inclusion, the complex represents a step forward for a homoleptic uranyl array ${ }^{4}$ in regard to the size of its defined cavity in that, here, it is indeed occupied by a hydrogen bonded guest (ammonium ion) and it is important to note that the capsule is formed in the presence of an additional counterion which does not quench emission at the uranyl centres.

\section{ASSOCIATED CONTENT}

\section{Accession Codes}

CCDC 1817366-1817368 contain the supplementary crystallographic data for this paper. These data can be obtained free of charge via www.ccdc.cam.ac.uk/data_request/cif, or by emailing data_request@ccdc.cam.ac.uk, or by contacting The Cambridge Crystallographic Data Centre, 12 Union Road, Cambridge CB2 1EZ, UK; fax: +44 1223336033.

\section{Supporting Information}

Figures S1-S3. This information is available free of charge via the Internet at http://pubs.acs.org/.

\section{AUTHOR INFORMATION}

\section{Corresponding Author}

*E-mail for P.T.: pierre.thuery@cea.fr

\section{ORCID}

Pierre Thuéry: 0000-0003-1683-570X

Youssef Atoini: 0000-0003-4851-3713

Jack Harrowfield: 0000-0003-4005-740X

\section{Notes}

The authors declare no competing financial interest.

\section{DEDICATION}

This paper is dedicated to Dr. Michel Ephritikhine on the occasion of his seventieth birthday.

\section{REFERENCES}

1. Andrews, M. B.; Cahill, C. L. Uranyl Bearing Hybrid Materials: Synthesis, Speciation, and Solid-State Structures. Chem. Rev. 2013, 113, 1121-1136.

2. Loiseau, T.; Mihalcea, I.; Henry, N.; Volkringer, C. The Crystal Chemistry of Uranium Carboxylates. Coord. Chem. Rev. 2014, 266267, 69-109.

3. Su, J.; Chen, J. S. MOFs of Uranium and the Actinides. Struct. Bond. 2015, 163, 265-296. 
4. Thuéry, P.; Harrowfield, J. Recent Advances in Structural Studies of Heterometallic Uranyl-Containing Coordination Polymers and Polynuclear Closed Species. Dalton Trans. 2017, 46, 13660-13667.

5. Thuéry, P.; Nierlich, M.; Baldwin, B. W.; Komatsuzaki, N.; Hirose, T. A Metal-Organic Molecular Box Obtained from Self-Assembling around Uranyl Ions. J. Chem. Soc., Dalton Trans., 1999, 1047-1048.

6. Thuéry, P. Two Novel Uranyl-Organic Frameworks with Cyclohexane-1,3-Dicarboxylate Ligands. CrystEngComm 2009, 11, 232-234.

7. Thuéry, P. A Lanthanide Ion-Decorated Uranyl-Organic TwoDimensional Assembly with all-cis 1,2,3,4,5,6Cyclohexanehexacarboxylic Acid. Cryst. Growth Des. 2010, 10, 2061-2063.

8. Mihalcea, I.; Falaise, C.; Volkringer, C.; Henry, N.; Loiseau, T. Room Temperature Crystallization of Trichlorodioxouranate $\left[\mathrm{UO}_{2} \mathrm{Cl}_{3}(\mathrm{~L})\right]$ Species in Molecular Assemblies Involving Aliphatic Dicarboxylate Linkers. Inorg. Chem. Commun. 2014, 44, 63-66.

9. Thuéry, P. A Highly Adjustable Coordination System: Nanotubular and Molecular Cage Species in Uranyl Ion Complexes with Kemp's Triacid. Cryst. Growth Des. 2014, 14, 901-904.

10. Thuéry, P. Increasing Complexity in the Uranyl Ion-Kemp's Triacid System: From One- and Two-Dimensional Polymers to Uranyl-Copper(II) Dodeca- and Hexadecanuclear Species. Cryst. Growth Des. 2014, 14, 2665-2676.

11. Thuéry, P.; Harrowfield, J. Uranyl Ion Complexes with all-cis-1,3,5Cyclohexanetricarboxylate: Unexpected Framework and Nanotubular Assemblies. Cryst. Growth Des. 2014, 14, 4214-4225.

12. Thuéry, P.; Harrowfield, J. Two-Dimensional Assemblies in f-Element Ion $\left(\mathrm{UO}_{2}{ }^{2+}, \mathrm{Yb}^{3+}\right)$ Complexes with Two Cyclohexyl-Based Polycarboxylates. Polyhedron 2015, 98, 5-11.

13. Thuéry, P.; Harrowfield, J. Coordination Polymers and CageContaining Frameworks in Uranyl Ion Complexes with rac- and (1R,2R)-trans-1,2-Cyclohexanedicarboxylates: Consequences of Chirality. Inorg. Chem. 2017, 56, 1455-1469.

14. Thuéry, P.; Harrowfield, J. Tetrahedral and Cuboidal Clusters in Complexes of Uranyl and Alkali or Alkaline-Earth Metal Ions with rac- and $(1 R, 2 R)$-trans-1,2-Cyclohexanedicarboxylate. Cryst. Growth Des. 2017, 17, 2881-2892.

15. Thuéry, P.; Harrowfield, J. Structural Consequences of 1,4Cyclohexanedicarboxylate cis/trans Isomerism in Uranyl Ion Complexes: from Molecular Species to 2D and 3D Entangled Nets. Inorg. Chem. 2017, 56, 13464-13481.

16. Garza, A. J.; Nag, M.; Carroll, W. R.; Goddard, W. A. III; Roberts, J. D. Conformational Preferences of trans-1,2- and cis-1,3Cyclohexanedicarboxylic Acids in Water and Dimethyl Sulfoxide as a Function of the Ionization State As Determined from NMR Spectroscopy and Density Functional Theory Quantum Mechanical Calculations. J. Am. Chem. Soc. 2012, 134, 14772-14780.

17. Kimura, K.; Watanabe, Y.; Suda, T.; Senda, H.; Hosoi, S.; Ohta, T.; Kunimoto, K. K. Crystal Structure of $(1 R, 2 R)$-trans-1,2 Cyclohexanedicarboxylic Acid- $(R)-1-$ Phenylethylamine Salt. Anal. Sci. 1999, 15, 609-610.

18. Smith, G.; Wermuth, U. D.; Williams, M. L. Resolution of the Chiral $(1 R, 2 S)$ Enantiomer of cis-Cyclohexane-1,2-dicarboxylic Acid in the Brucinium Salt 2,3-Dimethoxy-10-oxostrychnidinium (1R,2S)-2carboxycyclohexane-1-carboxylate Dihydrate. J. Chem. Crystallogr. 2012, 42, 555-559.

19. Groom, C. R.; Bruno, I. J.; Lightfoot, M. P.; Ward, S. C. The Cambridge Structural Database. Acta Crystallogr., Sect. B 2016, 72, 171-179.

20. Thuéry, P.; Villiers, C.; Jaud, J.; Ephritikhine, M.; Masci, B. UranylBased Metallamacrocycles: Tri- and Tetranuclear Complexes with $(2 R, 3 R, 4 S, 5 S)$-Tetrahydrofurantetracarboxylic Acid. J. Am. Chem. Soc. 2004, 126, 6838-6839.

21. Thuéry, P. A Nanosized Uranyl Camphorate Cage and its Use as a Building Unit in a Metal-Organic Framework. Cryst. Growth Des. 2009, 9, 4592-4594.

22. Thuéry, P.; Harrowfield, J. A New Form of Triple-Stranded Helicate Found in Uranyl Complexes of Aliphatic $\alpha, \omega$-Dicarboxylates. Inorg. Chem. 2015, 54, 10539-10541.

23. Pasquale, S.; Sattin, S.; Escudero-Adán, E. C.; Martínez-Belmonte, M.; de Mendoza, J. Giant Regular Polyhedra from Calixarene Carboxylates and Uranyl. Nature Commun. 2012, 3, 785-791.

24. Qiu, J.; Burns, P. C. Clusters of Actinides with Oxide, Peroxide, or Hydroxide Bridges. Chem. Rev. 2013, 113, 1097-1120.
25. Ling, J.; Hobbs, F.; Prendergast, S.; Adelani, P. O.; Babo, J. M.; Qiu, J.; Weng, Z.; Burns, P. C. Hybrid Uranium-Transition-Metal Oxide Cage Clusters. Inorg. Chem. 2014, 53, 12877-12884.

26. Sigmon, G. E.; Szymanowski, J. E. S.; Carter, K. P.; Cahill, C. L.; Burns, P. C. Hybrid Lanthanide-Actinide Peroxide Cage Clusters. Inorg. Chem. 2016, 55, 2682-2684.

27. Dembowski, M.; Olds, T. A.; Pellegrini, K. L.; Hoffmann, C.; Wang, X.; Hickam, S.; He, J.; Oliver, A. G.; Burns, P. C. Solution ${ }^{31}$ P NMR Study of the Acid-Catalyzed Formation of a Highly Charged $\left\{\mathrm{U}_{24} \mathrm{Pp}_{12}\right\}$ Nanocluster, $\quad\left[\left(\mathrm{UO}_{2}\right)_{24}\left(\mathrm{O}_{2}\right)_{24}\left(\mathrm{P}_{2} \mathrm{O}_{7}\right)_{12}\right]^{48-}$, and Its Structural Characterization in the Solid State Using Single-Crystal Neutron Diffraction. J. Am. Chem. Soc. 2016, 138, 8547-8553.

28. Hickam, S.; Burns, P. C. Oxo Clusters of $5 f$ Elements. Struct. Bonding (Berlin, Ger.) 2017, 173, 121-154.

29. Hooft, R. W. W. COLLECT, Nonius BV: Delft, The Netherlands, 1998.

30. Otwinowski, Z.; Minor, W. Processing of X-Ray Diffraction Data Collected in Oscillation Mode. Methods Enzymol. 1997, 276, 307-326.

31. Sheldrick, G. M. SHELXT - Integrated Space-Group and CrystalStructure Determination. Acta Crystallogr., Sect. A 2015, 71, 3-8.

32. Sheldrick, G. M. Crystal Structure Refinement with SHELXL. Acta Crystallogr., Sect. C 2015, 71, 3-8.

33. Farrugia, L. J. WinGX and ORTEP for Windows: an Update. J. Appl. Crystallogr. 2012, 45, 849-854.

34. Momma, K.; Izumi, F. VESTA: a Three-Dimensional Visualization System for Electronic and Structural Analysis. J. Appl. Crystallogr. 2008, 41, 653-658.

35. Blatov, V. A. TOPOS, Samara State University, Russia, 2004.

36. Thuéry, P.; Rivière, E.; Harrowfield, J. Counterion-Induced Variations in the Dimensionality and Topology of Uranyl Pimelate Complexes. Cryst. Growth Des. 2016, 16, 2826-2835.

37. Thuéry, P.; Harrowfield, J. Variations on the Honeycomb Topology: From Triangular- and Square-Grooved Networks to Tubular Assemblies in Uranyl Tricarballylate Complexes. Cryst. Growth Des. 2017, 17, 963-966.

38. Brachmann, A.; Geipel, G.; Bernhard, G.; Nitsche, H. Study of Uranyl(VI) Malonate Complexation by Time Resolved LaserInduced Fluorescence Spectroscopy (TRLFS). Radiochim. Acta 2002, 90, 147-153. 


\section{Counterion-Controlled Formation of an Octanuclear Uranyl Cage with cis-1,2-Cyclohexanedicarboxylate Ligands}

Pierre Thuéry, Youssef Atoini and Jack Harrowfield

Depending on the experimental conditions, in particular the nature of the potential counterions present, cis-1,2cyclohexanedicarboxylate reacts with uranyl ions to give either two-dimensional assemblies, or a discrete, octanuclear cage of unprecedented geometry, which includes an ammonium cation hydrogen bonded to uranyl oxo groups. This pseudo-cubic cluster differs from the tetrahedral ones obtained with trans-1,2-cyclohexanedicarboxylate and from other octanuclear cages involving different carboxylate ligands.

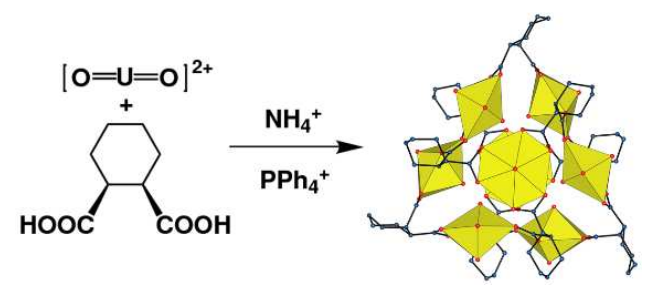

